$\begin{array}{ll} & \text { Etnográfica } \\ \text { etnográfica } & \text { Revista do Centro em Rede de Investigação em }\end{array}$

Antropologia

vol. 20 (3) | 2016

Vol. 20 (3)

\title{
As drogas em combate: usos e significados das substâncias psicoativas na Guerra Colonial Portuguesa
}

Drugs in combat: uses and meanings of psychoactive substances in the Portuguese Colonial War

\section{Vasco Gil Calado}

\section{(2) OpenEdition}

\section{Journals}

\section{Edição electrónica}

URL: https://journals.openedition.org/etnografica/4628

DOI: 10.4000/etnografica.4628

ISSN: 2182-2891

\section{Editora}

Centro em Rede de Investigação em Antropologia

\section{Edição impressa}

Data de publição: 1 outubro 2016

Paginação: 471-494

ISSN: 0873-6561

\section{Refêrencia eletrónica}

Vasco Gil Calado, «As drogas em combate: usos e significados das substâncias psicoativas na Guerra Colonial Portuguesa», Etnográfica [Online], vol. 20 (3) | 2016, posto online no dia 27 novembro 2016, consultado o 10 fevereiro 2022. URL: http://journals.openedition.org/etnografica/4628 ; DOI: https:// doi.org/10.4000/etnografica.4628

\section{(c) (†) 8}

Etnográfica is licensed under a Creative Commons Attribution-NonCommercial 4.0 International License. 


\section{As drogas em combate: usos e significados das substâncias psicoativas na Guerra Colonial Portuguesa}

\section{Vasco Gil Calado}

Apresentam-se as principais questões suscitadas pelo trabalho em curso acerca do uso de substâncias psicoativas na Guerra Colonial Portuguesa (1961-1974). São identificados alguns aspetos-chave que emergem das narrativas dos ex-combatentes acerca da sua experiência de guerra e que contextualizam um conjunto de práticas, entre elas o uso de drogas. Confirma-se o abuso de álcool e o uso de canábis entre os militares das forças armadas portuguesas envolvidas no conflito, numa altura em que em Portugal surgiam as primeiras iniciativas de combate às drogas. Tanto o consumo de bebidas alcoólicas como de outras drogas pode ser entendido como uma forma de lidar com a ansiedade e a violência do quotidiano.

PALAVRAS-CHAVE: substâncias psicoativas, Guerra Colonial Portuguesa, experiência de guerra, álcool, canábis.

Drugs in combat: uses and meanings of psychoactive substances in the Portuguese Colonial War - This paper presents the latest conclusions of an ongoing research on the use of psychoactive substances in the Portuguese Colonial War (1961-1974). The key aspects that emerge in the narratives of the former soldiers about their own war experience are identified. These aspects contextualize a set of practices, among them the use of legal and illegal drugs. Collected data show that the use of cannabis and the abuse of alcohol by Portuguese soldiers during this war was widespread, at the time when the first war-on-drugs initiatives were carried out in Portugal. The use of both alcoholic beverages and cannabis was, as research reveals, a way of dealing with anxiety and everyday violence.

KEYWORDS: psychoactive substances, Portuguese Colonial War, war experience, alcohol, cannabis.

CALADO, Vasco Gil (vascogil@gmail.com) - ISCTE-IUL; SICAD, Portugal. 


\section{INTRODUÇÃO}

Em junho de 1971, numa célebre conferência de imprensa, o presidente Richard Nixon declarou as drogas ilícitas o "inimigo número um" da sociedade norte-americana, o que para muitos autores marcou simbolicamente o início da chamada "guerra às drogas" (Bergen-Cico 2012; Nutt 2012; T. Rodrigues 2008; Courtwright 2001). No dia anterior, Nixon havia escrito uma mensagem ao Congresso dos Estados Unidos da América, explicando os moldes do paradigma que, apesar de cada vez mais contestado, ainda hoje domina a prática e, sobretudo, o discurso oficial e se afirmou praticamente hegemónico a nível mundial durante as décadas que se seguiram (Gezon 2016 [2012]; Cruz, Machado e Fernandes 2012). Os seus defensores advogavam então um mundo livre de drogas ilícitas e defendiam uma concertação de esforços no sentido da sua erradicação.

Esta é tida como uma resposta aos novos tempos de mudança que se viviam nos Estados Unidos da América, mais concretamente como uma forma de combater o uso crescente de substâncias psicoativas ilícitas por parte de jovens hippies e simpatizantes do movimento de contestação social que ficou conhecido como "contracultura" (Booth 2005), tendência que se intensificou na segunda metade da década de 60 do século XX. De facto, pela primeira vez em larga escala nas sociedades ditas ocidentais, o consumo de novas e velhas drogas ilícitas fazia-se fora de pequenos meios e "subculturas" (Manning 2014; Feixa 1998), liberalizando-se e estendendo-se a diferentes tipos de populações (Escohotado 2004 [1996]). ${ }^{1}$ Nos Estados Unidos da América, entre os novos consumidores incluíam-se jovens brancos de classe média e estudantes universitários, o que só por si fez aumentar a preocupação social e pôs em causa estigmatizações enraizadas que relacionavam o uso de drogas exclusivamente com determinadas minorias étnicas, subpopulações marginalizadas ou estilos de vida boémios.

No entanto, para a definição da estratégia de guerra às drogas adotada pela administração Nixon, foi tão ou mais importante o alarme social criado pelas constantes notícias e reportagens difundidas pelos media americanos acerca do elevado uso de canábis (marijuana), heroína e LSD por parte dos militares envolvidos na Guerra do Vietname (1965-1975) (Booth 2005). Estimativas da altura apontavam para que cerca de 10 a 25\% dos soldados norte-americanos presentes no Vietname fumassem heroína com regularidade (Martin 2012; Maraniss 2003).

$\mathrm{Na}$ esfera pública, as tropas norte-americanas de então eram representadas como um indisciplinado grupo de soldados maioritariamente sob o efeito constante de substâncias psicoativas ilícitas (Whalon 2004; Kuzmarov 2009). 
Assente num pânico moral (Cohen 2002 [1972]), o tema foi elevado à categoria de problema social, e muitos líderes de opinião expressaram o receio de que os militares constituíssem um foco de instabilidade e que o seu regresso e desmobilização se traduzissem numa súbita enchente de toxicodependentes na sociedade norte-americana (Stanton 1976; Inglis 1975). O que não veio a acontecer: de volta a casa, a grande maioria dos militares cessou os consumos de heroína (Robins 1993).

Apesar de toda a inaudita atenção mediática que o assunto suscitou na altura, a Guerra do Vietname não foi o primeiro conflito militar onde as drogas circularam mais ou menos livremente. Pelo contrário, historicamente as guerras foram amiúde um contexto de considerável ou intenso uso de substâncias psicoativas e um importante veículo para a sua difusão e massificação. O mito da seita fundada por Hassen Sabbah, no século XI, que teria o hábito de fumar haxixe antes dos combates, a canábis que os soldados de Napoleão trouxeram do Egito para França, a Guerra do Ópio, os dependentes de morfina na Guerra Civil Americana, o uso de anfetaminas e metanfetaminas na Segunda Guerra Mundial e, depois disso, na Guerra da Coreia são alguns dos casos mais frequentemente citados (Kan 2009; Kuzmarov 2009; Rasmussen 2008; Booth 2005; Escohotado 2004 [1996]; Lewis 2003 [1967]; Pollan 2001; Ribeiro 1995). Inúmeros são também os exemplos de guerras onde bebidas alcoólicas foram usadas pelos militares envolvidos, muitas vezes fazendo inclusivamente parte das rações de combate ou servindo como soldo (Bergen-Cico 2012; Kranzler e Korsmeyer 2009; Williams 2005). Consoante o caso, historicamente as substâncias psicoativas foram usadas em contexto de conflito militar sobretudo como estimulantes, como forma de alívio ou, mais recentemente, por razões recreativas.

Sensivelmente ao mesmo tempo que o exército norte-americano se envolvia militarmente no Extremo Oriente, em África decorria a Guerra Colonial Portuguesa (1961-1974), opondo as forças armadas portuguesas a movimentos independentistas africanos de guerrilha oriundos dos então territórios ultramarinos de Angola, Guiné e Moçambique. ${ }^{2}$

Como se verá, também os militares portugueses usaram e se serviram de substâncias psicoativas lícitas e ilícitas no decorrer de um conflito militar. Este artigo sintetiza as principais conclusões de três anos de pesquisa sobre o tema. ${ }^{3}$

2 A Guerra Colonial Portuguesa é também chamada Guerra do Ultramar ou Guerra de Libertação Nacional, se vista por outros prismas. Menos frequentemente, é também designada como Guerra(s) de África.

3 A pesquisa assenta em entrevistas não dirigidas (Devillard, Mudanó e Pazos 2012; Kvale 2006; Rubio 2006) realizadas com ex-combatentes do exército português que prestaram serviço na Guerra Colonial Portuguesa e foi complementada com uma recolha bibliográfica extensiva, focada essencialmente num conjunto de biografias, histórias de vida e relatos biográficos centrados na experiência de guerra em África. Num segundo momento, porque tal se justificou, estendeu-se a pesquisa [continua] 


\section{GUERRA COLONIAL PORTUGUESA}

A forma como os ex-combatentes falam e escrevem acerca da sua experiência de guerra no "Ultramar" é extremamente variável, indo de uma postura mais distanciada a uma posição mais vivida, de um tom pícaro e quase anedótico a um mais dramático e sofrido, de uma posição de explicação e enquadramento histórico e social a um registo puramente individualista e autocentrado. ${ }^{4}$ A própria experiência de guerra variou muito consoante o ano e o local onde o serviço militar foi prestado, sendo radicalmente diferente de região para região e de função para função. ${ }^{5}$ Por tudo isto, e tal já foi dito mil vezes, a Guerra Colonial Portuguesa não foi uma mas muitas guerras, porventura tantas quantas os militares envolvidos.

Há, no entanto, traços comuns ao conjunto dos testemunhos. Por exemplo, embora a guerra tenha terminado há mais de 40 ou 50 anos, a grande maioria dos entrevistados fala dela e de episódios lá vividos como se tudo se tivesse passado muito recentemente. Outros falam como se para eles a guerra nunca tivesse acabado (Loja 2013 [2002]; Janeiro 2012; Bastos 2008). Em muitos textos, perpassa uma vincada necessidade de acertar contas com o passado, de impedir que o vivido caia no esquecimento, de deixar escritos para memória futura e de homenagear os companheiros de luta, nomeadamente aqueles que morreram em combate. Também a ideia de que a experiência de guerra transforma e faz amadurecer os jovens à força é recorrente (Niza 2012; Ganhão 2007; Monteiro 2001).

Feito um esforço para identificar os principais eixos de análise, emergem três ideias-chave, relevantes na medida em que ajudam a contextualizar, enquadrar e explicar o uso de substâncias psicoativas naquele contexto específico. ${ }^{6}$

[continuação] ao ciberespaço (Calado 2006, 2009, 2013) e aplicou-se um inquérito online a ex-combatentes. O conjunto de narrativas e textos analisados é composto pelas entrevistas realizadas propositadamente, pelos textos editados em livro, pelos textos publicados no espaço digital que foram recolhidos e pelas respostas às perguntas abertas do questionário online, daqui para a frente designadas genericamente "testemunhos". Alguns dos argumentos apresentados resultam da troca de ideias com o meu colega Luís Vasconcelos e também com os professores Miguel Vale de Almeida, Brian O’Neill e, sobretudo, Francisco Oneto, a quem estou agradecido.

4 Quando aqui se fala de "ex-combatentes" ou, mais genericamente, de "militares", está-se a incluir somente aqueles que participaram na Guerra Colonial Portuguesa incorporados nas forças armadas portuguesas e a excluir os membros dos movimentos independentistas africanos. Da mesma forma, quando se fala em "militares portugueses" está-se a incluir militares africanos que lutaram do lado das tropas portuguesas.

5 Não foi o mesmo ter estado numa região pacificada ou numa região militarmente ativa, haver tido funções operacionais e cumprido missões no "mato" ou ficado cingido apenas a funções administrativas e não ter saído do quartel, por exemplo.

6 "Drogas" e "substâncias psicoativas" são aqui usadas como sinónimos e incluem todas as substâncias que, depois de ingeridas, condicionam o sistema nervoso central (estimulantes, depressoras ou alucinogénias), atuando sobre o estado de consciência, o humor ou, mais genericamente, o funcionamento cerebral. Neste sentido, tanto o álcool como a canábis, as duas substâncias discutidas neste artigo, [continua] 
Nos testemunhos dos ex-combatentes, tanto explícita como implicitamente, a Guerra Colonial Portuguesa tende a ser apresentada como: (a) um tempo de experimentação e de contacto com novas realidades; (b) uma experiência feita de grande tensão e estados de ansiedade constante; (c) um contexto de pouca preparação militar, alguma indisciplina e formas de contestação.

Para a grande maioria dos militares que nela participaram, oriundos da "Metrópole", a guerra em África foi, em muitos sentidos, um mundo admiravelmente novo. Excluindo o caso dos militares que foram recrutados localmente - "colonos" e "nativos", para usar as expressões da altura ${ }^{7}-$, tudo se passou num continente estranho, profundamente diferente do que a generalidade dos soldados portugueses conhecia: os cheiros, os sabores e os sons, a fauna e a flora, a escala e a dimensão, o clima, a paisagem e as cores, etc., tudo era novidade e muito foi vivido, sentido ou experimentado ali pela primeira vez (V. Santos 2013; Ferreira 2011 ; Oeiras 2009; A. L. Antunes 2005). Para mais, muitos dos militares portugueses que participaram na Guerra Colonial Portuguesa - de baixa patente, sobretudo - são apresentados como muito novos, pouco viajados, com baixas habilitações literárias e oriundos de um Portugal rural (M. J.L. Antunes 2015; Oeiras 2009), constituindo o serviço militar a sua primeira vivência fora da casa dos pais. Nesse sentido, o período de guerra, enquanto incursão num mundo "exótico", constituiu um óbvio corte com o quotidiano, uma pausa no percurso de vida (M. J. L. Antunes 2015; Niza 2012; Vardasca 2012). ${ }^{8}$ Como se verá, para alguns, entre as novas experiências tidas na guerra constam a ingestão de determinadas comidas e bebidas, ${ }^{9}$ mas também o uso de substâncias psicoativas lícitas (como bebidas alcoólicas específicas, destiladas ou de fabrico artesanal local, por exemplo, resultando por vezes na primeira experiência de um estado de embriaguez) e ilícitas (como a canábis) (Ferreira 2011).

são substâncias psicoativas. Ao contrário do sistema jurídico-legal, que separa claramente as duas substâncias, acompanha-se os argumentos de Geoffrey Hunt e Judith Barker (2001) de crítica à tradição das ciências sociais, e da antropologia em particular, de autonomizar o estudo de álcool e drogas ilícitas, criando duas tradições académicas distintas.

7 O discurso hegemónico acerca da Guerra Colonial Portuguesa tende a secundarizar ou omitir a experiência e a perspetiva dos militares de incorporação local - isto é, aqueles nascidos ou que viviam nos territórios africanos -, cujo número nas forças armadas portuguesas foi aumentando à medida que ia progredindo o conflito militar (Gomes 2013).

8 Os militares portugueses viram-se imersos num mundo "exótico", tanto do ponto de vista do mundo natural como do ponto de vista cultural, exprimindo nos seus registos biográficos espanto, fascínio e consciência das diferenças na natureza e na vida dos povos africanos.

9 Alguns militares, por exemplo, relatam a experiência de comer camarão cozido pela primeira vez (Oeiras 2009). Por outro lado, bebidas como a Coca-Cola ou a Pepsi eram de venda proibida na "Metrópole", mas de venda livre nas "colónias". Por causa disso, conta Vítor Santos, que participou na Guerra Colonial Portuguesa, em Moçambique, enquanto sapador de minas, "coca-cola [era o] nome dado pelos militares da metrópole aos naturais de Lourenço Marques” (2013: 112). 
Invariavelmente, fruto da própria natureza do conflito, a Guerra Colonial Portuguesa é descrita como uma experiência de desgaste, dura e difícil de suportar, tanto do ponto de vista físico e das condições materiais como do ponto de vista mental e psicológico. Enfrentar um movimento de guerrilha implica combater um inimigo que na maior parte das vezes não se vê e se esconde, que ataca quando não se espera e contra o qual há que estar sempre à defesa. Como refere Luís Oeiras, que participou neste conflito como alferes em Moçambique, "um combate de guerrilha é como um terramoto. Pode estoirar em qualquer altura, mas não se pode viver à espera debaixo de uma mesa" (2009: 39).

Aliás, para a generalidade da tropa convencional, ${ }^{10}$ tratou-se de uma guerra defensiva, procurando evitar emboscadas e ataques de minas, com poucas incursões ofensivas (e que muitas vezes não chegavam a resultar em confrontos). Por outro lado, os testemunhos estão cheios de referências a tempos mortos, de ócio e de inatividade, passíveis, no entanto, de serem interrompidos a qualquer instante por um ataque inimigo. Segundo Manuel Bastos, que esteve como alferes em Moçambique, "a vida de um soldado é feita de longos períodos de tédio, que alternam com curtos períodos de terror [...] porém nestes períodos de tédio é que verdadeiramente nos visita o medo, quando a adrenalina está baixa e a fantasia mais volátil que o fumo do cigarro" (2008: 169).

Recorrentemente é descrito um ambiente sufocante e concentracionário (M.J.L. Antunes 2015; A.L. Antunes 2005), marcado pelo isolamento, pelo stress e muita ansiedade, mesmo por quem viveu a guerra em regiões de menor atividade militar do inimigo (Sousa 2007; Lopes 1998). ${ }^{11}$ Era o inimigo quem conhecia e dominava o terreno, daí tirando óbvio benefício: de alguma forma, as tropas portuguesas eram em África um corpo estranho. Por tudo isto, os testemunhos incluem constantes referências a problemas mentais e episódios de descompensação, descritos pelos próprios ou relatados por terceiros, tipificados na figura do "cacimbado" (Janeiro 2012; Bastos 2008). ${ }^{12}$ De uma forma genérica, a saúde mental dos ex-combatentes das forças armadas presentes na Guerra Colonial Portuguesa degradava-se visivelmente à medida que o tempo de comissão ia passando (Loja 2013 [2002]; Aguiar 2007), atingindo o ponto mínimo de sanidade (se é que tal pode ser medido) na altura da rendição, para

10 Excluem-se as chamadas "tropas especiais" - comandos, fuzileiros, paraquedistas, entre outras de natureza ofensiva e com missões operacionais específicas, maioritariamente de ataque.

ll A experiência de guerra inclui casos de militares que não chegaram a disparar um tiro e/ou não se depararam com o inimigo uma única vez. Neste sentido, ter "ido à guerra" é mais do que a vivência operacional e militar.

12 Manuel Bastos inicia assim o seu livro Cacimbados: A Vida por Um Fio: "Chamavam esgazeados aos ex-combatentes da Grande Guerra e cacimbados aos da Guerra Colonial Portuguesa, associando os seus traumas, no primeiro caso às bombas de gás e no segundo ao clima de África" (2008: 9). Também Maria José Lobo Antunes, na sua recente etnografia de uma companhia militar que esteve em Angola entre 1971 e 1972, aborda a figura do "cacimbado", designando-a como "uma suave loucura" responsável por tornar os "militares capazes dos mais impensados disparates" (2015: 150). 
espanto e choque das tropas acabadas de chegar à frente de combate (M.J.L. Antunes 2015; Janeiro 2012; Mata 2012; Pereira 2011).

Por último, perpassa nos testemunhos uma sensação de que os militares envolvidos na Guerra Colonial Portuguesa se sentiam "carne para canhão", manifestando amiúde uma certa antipatia e desdém em relação aos comandantes e, sobretudo, às chefias de topo e aos "senhores da guerra", tidos como os responsáveis pela dura situação que se sentiam obrigados a enfrentar (Loja 2013 [2002]; Aguiar 2007; A. L. Antunes 2005). Em alguns casos, tal pareceu resultar num afrouxar da disciplina militar e em atos de desobediência e outros que colidiam com as regras de conduta militar. Por outro lado, para os ex-combatentes, o conceito de "camaradagem" (T.M. Silva 2007) foi, em certo sentido, mais relevante do que os de "pátria" ou "dever patriótico" (Sá 2009) - o dever sentido era sobretudo para com os camaradas de armas. A nível pessoal, portanto, o propósito último da guerra travada parece não ter sido lutar pela pátria mas, pura e simplesmente, sobreviver e chegar ao fim da comissão vivo, são e inteiro. Como tal, muitos ex-combatentes declaram ter feito a guerra com pouca convicção - mesmo aqueles que se ofereceram como voluntários -, daí derivando, mais uma vez, uma série de pequenos e grandes atos de indisciplina e fabrico de regras próprias. Para mais, perpassa também nos testemunhos um claro sentimento de impreparação militar e operacional (Lopes 1998), aliado a uma carência no que toca aos meios materiais disponíveis e às fracas condições de vida na maior parte dos quartéis - em particular naqueles localizados em zonas mais remotas -, o que contribuiu para desvincular os militares de causas ideológicas (V. Santos 2013; Mata 2012; Vardasca 2012) e favoreceu formas de contestação (como o Cancioneiro do Niassa, por exemplo). ${ }^{13}$

É tendo este cenário como pano de fundo que os ex-militares entrevistados enquadram e contextualizam um conjunto de práticas e "vícios" ${ }^{14}$ que tiveram lugar na Guerra Colonial Portuguesa: jogo, indisciplina, violência, atrocidades, prostituição, homossexualidade e também uso e abuso de substâncias psicoativas (Alexandre 2015; Martins 2003). Uns são descritos como transversais e generalizados, outros como interditos, alguns foram alvo de censura social, outros foram praticados sobretudo longe dos olhares públicos, mas todos são hoje explicados à luz da natureza do conflito militar e dos seus condicionantes.

13 O Cancioneiro do Niassa consiste num conjunto de adaptações de fados e canções em voga (de Bob Dylan a José Afonso), que, de forma humorística e sarcástica, abordam a temática da Guerra Colonial Portuguesa do ponto de vista do soldado e das condições de vida. As adaptações foram feitas por militares portugueses estacionados na região do Lago Niassa, em Moçambique, e tornaram-se rapidamente populares em muitos quartéis de outras regiões, servindo como uma forma de contestação à ordem estabelecida e, sobretudo, à cadeia de comando.

14 De forma provocatória, "vício" é aqui entendido num duplo sentido: como algo que é considerado adictivo e compulsivo e, simultaneamente, como algo que desafia a moral e pode ser visto como transgressão e/ou um desvio às normas morais. 


\section{USOS DE ÁLCOOL E OUTRAS DROGAS}

A Guerra Colonial Portuguesa é também feita de sombras e silêncios (Roque 2004), onde cabem os usos de álcool e outras drogas. Na sua historiografia oficial (J.F. Antunes 1995; Garcia 2010; Teixeira 2001; Afonso e Gomes 2000), o consumo de bebidas alcoólicas geralmente não merece mais do que uma nota de rodapé, enquanto o uso de drogas ilícitas é completamente ignorado, omitido ou considerado irrelevante. ${ }^{15}$ No entanto, na história oficiosa - isto é, aquela que se faz de depoimentos e registos (auto)biográficos, necessariamente parciais e nem sempre objetivos -, o uso de substâncias psicoativas tem um outro relevo: às bebidas alcoólicas é atribuído um papel central na vida quotidiana dos militares das forças armadas portuguesas envolvidos na Guerra Colonial, enquanto é possível encontrar nos testemunhos referências - ainda que muito mais veladas e esporádicas, é certo - ao uso de canábis, na forma de erva fumável, conhecida como liamba em Angola e suruma em Moçambique, tanto por parte da população africana como por parte das tropas portuguesas.

De acordo com os relatos, pode dizer-se que indiscutivelmente o álcool foi a substância psicoativa mais usada na Guerra Colonial Portuguesa, seguindo-se o tabaco e só depois todas as outras, a larga distância. De facto, dificilmente um ex-combatente da Guerra Colonial Portuguesa parece ser capaz de falar da sua vivência de guerra sem fazer menção às bebidas alcoólicas, com destaque para a cerveja, tal era a sua importância no dia-a-dia dos militares portugueses em África. Exceto em saídas operacionais para o "mato”, o álcool era uma presença constante, tanto em ocasiões especiais como no mais banal dos dias. ${ }^{16}$

Segundo os ex-combatentes, no que à Guerra Colonial Portuguesa diz respeito, para muitos a ingestão maciça de bebidas alcoólicas começou cedo, logo a bordo dos navios que transportavam as tropas portuguesas até aos territórios africanos (Alexandre 2015; Ferreira 2011; Oeiras 2009; Roque 2004). Para mais, tanto no meio do oceano como, mais tarde, em boa parte dos aquartelamentos africanos, a água era um bem escasso e tendencialmente de má qualidade, o que, juntamente com o clima abrasador, favorecia o consumo de bebidas alcoólicas, normalmente ingeridas frescas ou geladas.

Como já referido, entre as diferentes bebidas alcoólicas consumidas durante o conflito, destaca-se a cerveja. De caráter transversal, pode considerar-se a bebida emblemática da Guerra Colonial Portuguesa: consumida pela maioria

15 Como refere Luís Oeiras, no seu livro de memórias Mueda-Lua, a história política e social da Guerra Colonial é extensa e exaustiva, mas a dos combatentes não (2009: 9).

$16 \mathrm{Na}$ Guerra Colonial Portuguesa, de acordo com os testemunhos, a regra de não haver consumo de bebidas alcoólicas durante operações militares era genericamente cumprida. No entanto, alguns ex-combatentes confirmam a ingestão de bebidas alcoólicas durante saídas operacionais, não obstante tal ser consensualmente considerado algo perigoso e uma inconsciência. 
dos militares, independentemente da ocasião, da hora do dia, da função ou da patente militar. Vendidas mais caras, bebidas destiladas, como whisky, gin, aguardente e outras, eram consumidas sobretudo por militares graduados, que, na sua condição de oficiais e sargentos, tinham direito a comprar e/ou eram-lhes oferecidas determinadas bebidas destiladas por mês. Embora não lhes fossem vedadas, as bebidas destiladas eram muito menos consumidas por militares não graduados, por serem vendidas mais caras do que a cerveja. O preço limitava assim o acesso a este tipo de bebidas alcoólicas e impunha uma clara barreira hierárquica. ${ }^{17}$ Ao contrário da cerveja, que era em geral de produção local, as bebidas destiladas e o vinho iam de Portugal continental.

A importância do álcool para as tropas era reconhecida tanto por soldados como pelas chefias militares. De facto, tal como os géneros alimentares, as munições ou a correspondência, as bebidas alcoólicas faziam parte da logística militar e, por conseguinte, nunca faltavam nos quartéis portugueses, por mais remota que fosse a sua localização, sob pena de perturbar a paz social e abalar o moral.

José Niza, que, entre 1969 e 1971, esteve presente na Guerra Colonial Portuguesa como médico de uma companhia militar em Angola, conta no seu livro de memórias, Golden Gate (2012), como a decisão governamental de limitar o acesso às bebidas alcoólicas nos quartéis, em 1971, causou uma enorme revolta entre as tropas portuguesas em África, acabando por ser revertida apenas três semanas depois. Apelidando a decisão de inoportuna e até cruel num aerograma escrito por alturas dessa decisão política, o médico revela bem como o consumo de álcool, mesmo se excessivo, era entendido pelos oficiais como algo que cumpria um importante papel social, nomeadamente uma forma de escape e alívio, pelo que limitar o seu uso causaria mais mal do que bem.

"Outro problema que cá temos é o das quantidades astronómicas de cerveja que estes tipos bebem. Uma loucura! Muitos deles, quando chegam à cantina, em vez de pedirem uma cerveja, pedem meia grade! [...] O seu tranquilizante é o álcool, é com ele que se sentem mais animados, é ele que lhes tira do pensamento os problemas [...]. Devo tirar-lhes a bebida? Devo tirar-lhes o biberão, a eles, que na realidade são crianças ingénuas e ignorantes a quem disseram que eram homens, a quem deram uma espingarda, a quem lançaram para uma guerra onde muitos vão ficar? Devo tirar-lhes a única coisa que para além do correio os mantém vivos?" (Niza 2012: 46-47).

17 A regra geral era que os quartéis portugueses em África tivessem espaços diferentes para praças e graduados comerem e beberem, acontecendo por vezes que sargentos e oficiais partilhavam o mesmo refeitório, mas tinham espaços autónomos para adquirir e consumir bebidas alcoólicas (messe de oficiais e bar de sargentos). 
Para confirmar esta relação entre o álcool e o alívio emocional durante a Guerra Colonial Portuguesa, incluiu-se uma pergunta aberta no questionário online aplicado junto de ex-combatentes: "No caso de ter sentido stress durante a guerra em África, na altura como lidava com isso? O que fazia para se libertar da pressão?" 18 Sem surpresa, muitos ex-militares declararam que o consumo de bebidas alcoólicas era uma das principais formas de lidar com a pressão e a ansiedade (que a grande maioria reconhece ter sentido), sendo mesmo para alguns a mais importante. Assim, juntamente com o convívio, a música, a prática de desporto e, no caso de militares mais graduados, a escrita e a leitura, o consumo de bebidas alcoólicas destaca-se como um importante aliviador de tensão emocional. Eis algumas respostas à pergunta colocada no questionário online em novembro de 2015:

- "Passei por vários períodos de grande stress, nomeadamente os dois meses de espera por substituto depois de cumprir os dois anos de comissão. Lembro-me que a minha libertação era o álcool".

- "Procurávamos no tempo livre abster-nos de tudo o que nos envolvia: copos, música, grandes amizades e muita confiança entre as chefias”.

- "Fingia que não havia stress. Copos, cartas, bola e convívio com os camaradas".

- "Nas alturas de maior pressão bebia".

- "Bebia até à inconsciência".

- "Embebedava-me".

- "Bebia muitíssimo".

- "Bebia para dormir".

- "Farra e cerveja".

- "Álcool e tabaco com força".

- "Fumava e bebia whisky e cerveja".

- "Bebia e jogava".

- "Whisky e poker".

" "Whisky, bridge y putas".

- "Procurava abstrair-me, distraindo-me com amigos e bebendo".

- "Lia, bebia e tocava guitarra".

- "Saía para caçar e muito álcool".

- "Dava-lhe com uns bioxenes [calão para o whisky]".

18 A pergunta era colocada antes de no questionário se falar de álcool e drogas, pretendendo-se, assim, evitar o enviesamento das respostas. 
- "A camaradagem era muito grande e por isso se alguém estivesse em baixo havia sempre um amigo. Além disso havia muito whisky..."

Não é por acaso, então, que a cantina, o bar dos soldados e a messe de oficiais e sargentos eram locais de grande importância simbólica em qualquer quartel ou base militar da Guerra Colonial Portuguesa, servindo mais do que como mero ponto de aquisição de bebidas alcoólicas.

Nos quartéis as bebidas alcoólicas eram vendidas mais baratas - para uso exclusivo das forças armadas portuguesas -, o que, intencionalmente ou não, favorecia e incentivava o consumo de álcool. ${ }^{19}$ Não obstante o seu baixo preço, era na aquisição de bebidas alcoólicas que grande parte dos militares gastava uma importante fatia do dinheiro que lhe era entregue mensalmente ("pré"), o que revela bem o nível de consumo de álcool na Guerra Colonial Portuguesa.

Embora retrospetivamente o nível geral de consumo de bebidas alcoólicas seja hoje consensualmente considerado elevado pelos ex-combatentes, só em casos raros e extremos estes falam de alcoolismo. ${ }^{20}$ Mesmo se visto como "exagerado", o uso de bebidas alcoólicas tende a não ser visto pelo prisma da patologia e da ordem biomédica, sendo considerado normal e justificado, quase nunca condenado ou denegrido, na medida em que, como se viu, os militares da Guerra Colonial Portuguesa lhe atribuem um papel terapêutico: nas condições descritas, o álcool servia de equilibrador emocional e nesse sentido era tido como indispensável à boa saúde mental. É, por exemplo, a opinião de Alcino Ferreira, que esteve como furriel em Moçambique, e de José Leão (pseudónimo), que esteve em Angola como cabo enfermeiro, e que resumem muito do que atrás foi dito acerca do álcool:

"Bebia-se muito, no meu pensar, devido a diversas situações: à alta pressão passada em zonas de combate, a não se saber se haveria um amanhã, à solidão, à questão de o tempo de ócio ser muito, aos quase sempre pensamentos terríveis e inoportunos que teimavam em não nos largar, aos custos nulos e aos proveitos mais do que suficientes, tudo isso proporcionava a vadiagem e estroinice...!" (Ferreira 2011: 128)

19 António Lobo Antunes, que entre 1971 e 1972, esteve presente na Guerra Colonial Portuguesa como médico militar em Angola, revela nas suas cartas enviadas de África para a mulher, entretanto reunidas em livro, o quão baratas eram vendidas as bebidas alcoólicas nos quartéis. De facto, embora não bebesse, o médico aproveitava para as comprar e enviar para Lisboa: "Como todos os meses compro uma garrafa, já vou em 4 de uísque. Vou agora mudar-me para os conhaques, gins, etc., de modo a que, quando voltar, tenhamos uma boa garrafeira. São tudo marcas ótimas, e saem a cerca de 100.00 cada. Parece-me que vale a pena" (2005: 175).

20 Por exemplo, os entrevistados tendem a associar o alcoolismo sobretudo a casos em que o consumo excessivo de álcool era um hábito anterior ao serviço militar. Por outro lado, alcoólico não era quem bebia muito, mas sobretudo quem bebia constantemente, quem "não sabia beber" ou não aguentava os seus efeitos e se embriagava recorrentemente ("maus vinhos"). 
"Normalmente havia sempre uma razão não específica para se beber, bebia-se por camaradagem, por convivência, e porque o próprio clima convidava a fazê-lo, poderia haver num ou noutro razões de ordem psicológica, de saudade da família, que nem sempre eram exteriorizadas. Bebia-se para comemorar o regresso de uma operação no mato, em que tudo tinha corrido pelo melhor, ou seja, sem mortos nem feridos, bebia-se porque se ia para uma ação no mato, e não se sabia quem, ou se se iria voltar, bebia-se porque poderia ser a última, bebia-se porque alguém fazia anos, ou porque alguém pagava umas rodadas, enfim, bebia-se porque estar vivo, por si só, já era um motivo" [entrevista eletrónica, 26/3/2015].

Por outro lado, muitas vezes os testemunhos dão conta de que o álcool era um dos principais fatores que contribuíam para desencadear episódios de descompensação emocional (descritos como recorrentes), além de potenciar condutas irresponsáveis ou consideradas incorretas e de estar igualmente associado a muitos dos acidentes, nalguns casos com desfechos fatais (nomeadamente em episódios trágicos com armas de fogo). Essa vertente das bebidas alcoólicas tende, no entanto, a ser claramente desvalorizada ou, pelo menos, a ser secundarizada face à utilidade das mesmas num contexto como o da Guerra Colonial Portuguesa.

Em relação às drogas ilícitas, o conhecimento acerca do seu uso durante o conflito é bastante mais escasso, impreciso e menos bem documentado, o que levou a que se recorresse essencialmente a testemunhos orais. Com base num intenso trabalho de triangulação de informação dispersa, é possível confirmar o seu uso na Guerra Colonial Portuguesa, mas não tanto o seu significado e a sua história social.

Não obstante todas as lacunas de informação, parece indiscutível que a canábis foi a substância psicoativa ilícita mais consumida neste conflito militar, nomeadamente em Angola e em Moçambique, países onde, ao contrário da Guiné, o consumo da planta era então uma prática antiga instituída junto de parte da população (Valentim 2012; Silva 2003; Fabian 2000; Toit 1976). ${ }^{21}$

Infelizmente, a produção antropológica e o saber etnográfico acumulado acerca dos povos de Angola, Guiné e Moçambique nunca deram muita atenção ao uso de substâncias psicoativas lícitas e, muito menos, ilícitas. Sobre a canábis e outras drogas que não o álcool na África portuguesa, é possível encontrar apenas referências dispersas e geralmente laterais (Carvalho 1898; Welwitsch 1862), as mais antigas das quais remontam ao período dos missionários, como

21 Em contrapartida, alguns ex-combatentes que estiveram na Guiné durante a Guerra Colonial Portuguesa referem o consumo, quase sempre experimental e esporádico, de noz de cola, fruto de plantas ricas em cafeína e com efeito estimulante, que era usado tradicionalmente em algumas regiões da parte ocidental do continente africano (Lovejoy 2007 [1995]). 
o frade João dos Santos (1999 [1609]), no século XVII, e dos exploradores de África, como Paiva Couceiro (1892), Capelo e Ivens (2010 [1881]) e outros (Rosa e Verde 2013; Heintze 2010 [1999]), no século XIX.

Uma coisa é certa: as tropas portuguesas bebiam o álcool que era disponibilizado pela intendência militar, mas fumavam as drogas que encontravam por si próprias, tendo desenvolvido com a liamba e a suruma uma relação que nunca estabeleceram com as bebidas alcoólicas tradicionais africanas, de fabrico artesanal. De uma forma geral, foi algo com que se depararam, não um bem que trouxessem consigo, que já conhecessem ou que procurassem ativamente. Aliás, tendencialmente os militares envolvidos na Guerra Colonial Portuguesa - como a maior parte dos jovens portugueses seus contemporâneos, de resto - não tinham um conhecimento prévio acerca das drogas em geral, e dos efeitos psicoativos da canábis em particular, conhecimento que era em geral muito escasso e difuso. Neste sentido, o consumo de canábis foi uma das novas e não antecipadas experiências por que passaram alguns ex-combatentes em terras africanas.

Tudo indica que o conhecimento acerca da canábis e, consequentemente, o seu uso tenham aumentado com o desenrolar da própria guerra (Ribeiro 1999), dependendo da região, do tipo de tropa e até da unidade militar, beneficiando da crescente "africanização" do contingente militar. Nesse sentido, o consumo de canábis pode ser visto como um processo de aprendizagem que dependia de personagens-chave com ligações às populações locais (que depois introduziriam o uso da planta no seu círculo de relações). ${ }^{22}$ Não é por acaso que os militares portugueses colocados em quartéis situados em zonas muito remotas, sem aldeamentos nas imediações, tendem a não ter tido contacto com esta substância. ${ }^{23}$ De acordo com os testemunhos, a canábis que circulava por entre os militares portugueses provinha das populações africanas, sendo comprada, trocada, recolhida ou até roubada nos aldeamentos próximos dos quartéis portugueses (Janeiro 2012), ou então capturada ao inimigo (Marta 2000).

Rui Martins (pseudónimo), que esteve em Moçambique como alferes entre 1971 e 1974, refere os esquemas de circulação da canábis por entre as tropas portuguesas e como então se estava longe do conceito de "tráfico de droga":

"A mim davam-me. Eram os africanos que tinham esse conhecimento. Por vezes achavam aquilo uma coisa natural, era como dar tremoços para a cerveja, outras vezes vendiam por valores irrisórios. Os preços eram muito

22 Entre estas personagens-chave destacavam-se os soldados de incorporação local que serviam no exército português, e cujo número foi crescendo com o decorrer do conflito (F. Rodrigues 2012).

23 Tudo indica que, pelo contrário, em pontos nevrálgicos e de confluência dos militares - como a cidade de Mueda, em Moçambique -, a canábis tinha uma presença mais forte. 
baratos. Na maior parte das vezes davam. [...] E portanto as pessoas fumavam, era barato, muitas vezes não custava nada, havia pessoas que sabiam ir ao campo buscar a marijuana como cá são capazes de ir buscar papoilas" [entrevista presencial, 31/1/2015].

Ao contrário do que se passa com as bebidas alcoólicas, a grande maioria dos testemunhos publicados não faz a mínima menção ao uso de canábis. Alguns registos biográficos fazem menção ao uso de liamba e suruma durante a guerra mas não lhe dedicam atenção (Vardasca 2012; A.L. Antunes 2005), ou então referem-nas de forma lateral (Janeiro 2012; Marta 2000) ou condenatória, criando distância (Ferreira 2011; Aranha 2005; Martins 2003). Também a recolha de informação no ciberespaço permitiu encontrar referências ao uso de canábis por parte das tropas portuguesas, embora estas sejam raras e muitas vezes indiretas: tendencialmente o tema não é abordado diretamente mas através de metáforas, muitas vezes num tom irónico e com recurso a duplos sentidos.

No entanto, quando se pergunta por esta planta a ex-combatentes, uma boa parte tem algo a dizer sobre o assunto, seja porque consumiu ou assistiu ao seu consumo, seja porque tem notícia por terceiros do seu uso na Guerra Colonial Portuguesa. Não é, de todo, um assunto totalmente desconhecido, ainda que geralmente não seja falado. De facto, a maior parte dos entrevistados no âmbito da presente investigação teve contacto direto ou ouviu falar do uso da planta durante o conflito.

$\mathrm{O}$ inquérito online incluiu duas perguntas abertas com o propósito de confirmar o uso de canábis na Guerra Colonial Portuguesa: uma questionava o conhecimento do fenómeno ("Como descreveria o consumo de marijuana/liamba/suruma durante a guerra em África por parte das tropas portuguesas?"), outra o contacto direto com a planta ("Consumiu marijuana/liamba/suruma durante a guerra em África?").

A análise das respostas permite chegar a duas conclusões: a ausência de consumo de canábis por parte das tropas portuguesas na Guiné e um consumo relevante em Angola e Moçambique. De entre os 210 respondentes, todos aqueles que estiveram na Guiné afirmam não ter consumido a planta e desconhecer por completo o seu uso no território durante a guerra. O mesmo não se passa com os respondentes que estiveram em Angola e Moçambique: $15 \%$ dos militares que fizeram a guerra naqueles territórios afirmam ter consumido canábis, enquanto outros $25 \%$ afirmam ter assistido ao consumo ou tido conhecimento direto disso. Feitas as contas, dos respondentes que estiveram em Angola e Moçambique durante a Guerra Colonial Portuguesa, perto de metade $(40 \%)$ declaram ter tido um contacto direto com a planta.

Mas se é facilmente comprovável o consumo de canábis (e até, de alguma forma, possível estimar a dimensão do fenómeno) entre as tropas portuguesas 
que estiveram na Guerra Colonial, mais difícil é perceber o seu significado e fazer a sua história social. Em geral, o tom com que os entrevistados falam acerca do uso pessoal de canábis revela desconforto e vontade de evitar ou, pelo menos, desvalorizar a questão, tornando claro que este é um assunto incómodo, acerca do qual se dizem sobretudo coisas genéricas e não pessoais, o que está certamente relacionado com o seu caráter ilícito. Tal dificulta a investigação, mas ao mesmo tempo revela que as drogas não podem ser postas à parte do contexto social e que o discurso sobre elas é condicionado histórica e socialmente. De tão presente e recorrente, este silêncio adquiriu uma importância central, levantando questões.

A tónica dos discursos é colocada no desconhecimento, como se de alguma forma atenuasse ou desculpasse uma prática que é hoje vista como ilícita: todos os ex-combatentes entrevistados, tanto presencialmente como por via eletrónica, declaram que, à data, não estavam informados acerca das drogas e que não havia uma clara perceção de que o uso de canábis era algo proibido. Como já referido no início, a noção de "droga" enquanto problema social (Fernandes 2009) emerge no mundo ocidental ao mesmo tempo que decorre a Guerra Colonial Portuguesa. No entanto, no Portugal dos anos 60 e meados de 70 do século XX, o conhecimento sobre as drogas e o contacto com as substâncias proibidas eram invulgares e estavam limitados principalmente a uma pequena fatia da população, constituída essencialmente por jovens urbanos das grandes cidades (Costa 2007; Dias 2007; Ribeiro 1995), pelo que o conceito era algo mais abstrato do que concreto, não algo palpável e bem definido.

Do pouco que os seus consumidores estão dispostos a falar, ${ }^{24}$ pode dizer-se que a canábis era usada na guerra de África como uma forma de ajudar a relaxar, "espantar o medo", aliviar a ansiedade e escapar à angústia (Vardasca 2010) - que naquele contexto, de acordo com os testemunhos, assumiam uma dimensão colossal. Normalmente em associação com as bebidas alcoólicas, o consumo de canábis tanto podia ser feito em pequenos grupos como de forma isolada. Tendia a ser discreto mas não se tratava de algo propriamente secreto e/ou algo que, por si só, desse origem a castigos disciplinares.

Luís Leal (pseudónimo), que esteve como soldado condutor em Moçambique entre 1971 e 1973, destaca-se como informante privilegiado, por falar abertamente acerca do uso pessoal de canábis na guerra, que define como recorrente enquanto esteve em zona operacional:

"Eh pá, a gente fumava aquilo. Pá, a gente ia para uma operação e parecia que íamos para um baile. Uma despreocupação total. Quer dizer, aquele medo, coiso e tal, não. Claro que não íamos para o mato a rir, não é, nem a 
dançar. Mas íamos tão despreocupados que aquilo parecia que nem estávamos em guerra. E a gente ia, fazíamos as operações. Eu fumei bastante. Bastante daquilo. Porque era um escape que eu tinha. Eu não podia viver sem aquilo lá. [...] A gente queria é ir para o mato tranquilos, sem preocupações. E aquilo: 'eh pá, tu vais para o mato e parece que não vais, esse medo todo sai, sai fora de ti, pá', não sei quê" [entrevista presencial, 13/2/2015].

Também Rui Martins, atrás já apresentado, descreve o consumo de canábis como generalizado em Moçambique e, mais do que isso, de alguma forma incentivado pelos pares e ignorado pelas chefias militares:

"Havia uma questão psicológica, como toda a gente fumava marijuana, havia a ideia que quem não fumasse marijuana era maricas, ou qualquer coisa. [...] As chefias achavam que cada um fizesse o que quisesse. Não havia qualquer proibição, toda a gente sabia que toda a gente fumava a dita liamba - ou como chamava-se lá, suruma, a expressão que era usada em Moçambique. De tal maneira que se tornou uma adjetivação: 'eh, pá, isso é só suruma', quer dizer que um gajo estava a ficar parvo, pá. Mas ele estava a ficar parvo não era por isso, estava a ficar parvo porque estava farto da guerra [risos], não era por causa de fumar suruma" [entrevista presencial, $31 / 1 / 2015]$.

Claro que, por cada informante que considera o consumo de liamba e suruma uma prática habitual na Guerra Colonial Portuguesa, nomeadamente em Angola e Moçambique, se encontram dois ou três que afirmam o contrário.

Seja qual for a verdadeira dimensão do uso de canábis por parte das tropas portuguesas envolvidas no conflito, tudo indica que a grande maioria dos militares cessou os consumos aquando do regresso a casa, tal como se passou, aliás, no caso dos veteranos da Guerra do Vietname. Se bem que num processo mais complicado e demorado, segundo os próprios, também o consumo de bebidas alcoólicas foi igualmente sendo reduzido na generalidade dos casos, à medida que se foi procedendo ao reajuste face ao novo quotidiano e à passagem para a vida civil. Tal reforça a ideia de que o uso de substâncias psicoativas é algo que é intrinsecamente condicionado pelo contexto social e pelo conjunto de motivações e expetativas dos seus utilizadores.

No seu livro de memórias da guerra, José Manuel Martins, que esteve como primeiro-cabo no norte de Angola, entre 1972 e 1973, resume muito do que foi dito atrás acerca da canábis:

"Na década de setenta do século passado, havia consumo de droga nos quartéis! Em Zau-Évua, alguns militares consumiam droga, fumavam, pelo menos, liamba. No âmbito fechado, onde o moral não era alto, o consumo 
constituía mais um meio de 'evasão', de resposta ao isolamento e à desmotivação. [...] Não existiam intuitos de 'tráfico': quem tinha, tinha, e, por vezes, 'facilitava' aos interessados, que, mais tarde, faziam o mesmo. Não havia, embora possa admitir estar errado, consciência dos malefícios do consumo de droga; ao contrário, os consumidores achavam que o uso da liamba favorecia os relacionamentos, descomplexava e fazia esquecer as dificuldades do momento! Não se falava, é certo, de cocaína ou heroína nem dos horrores que o respetivo consumo implicava. Estávamos apenas no início da década de setenta, numa sociedade encerrada em si mesma, sem abertura ao exterior, onde apenas as ondas de rádio nos levavam para bem longe, embora sob todas as cautelas possíveis. Nas circunstâncias, o consumo de droga visava mais a 'descontração', o alívio da tensão em que se vivia. Não mais do que isso" (Martins 2003: 152).

\section{PALAVRAS FINAIS}

As drogas entram na Guerra Colonial Portuguesa desde o início: quando em 1961 se dão em Angola os primeiros ataques levados a cabo por independentistas ligados à UPA e ao MPLA, logo na imprensa portuguesa os "terroristas" são descritos como "bárbaros assassinos" e é feita uma "ligação sistemática ao consumo de drogas e ao recurso a feitiços" (M.J.L. Antunes 2015: 64). ${ }^{25}$ De facto, na altura foi repetidamente dito que os autores dos massacres agiam cegos e enlouquecidos, sob influência direta de canábis e cachipembe ${ }^{26}$ (Wheeler e Pélissier 2009 [1971]; Valahu 1968).

Não era inaudita a relação entre canábis e violência em África (Bergen-Cico 2012). O caso mais frequentemente citado é o dos guerreiros zulus da atual África do Sul, que tinham por hábito fumar canábis antes de entrar em batalha (Toit 1975), prática que o explorador britânico David Livingstone registou no século XIX (James e Johnson 1996). Mas já antes disso, em 1767, o governador de Moçambique, Pereira do Lago, falava dos cafres da Ilha de Moçambique, que "bêbados de um fumo infernal e pernicioso se alucinam para toda a qualidade de homicídios" (citado em L. D. Antunes 2006: 205). ${ }^{27}$

25 Na primeira página do Diário de Lisboa, de 11 de fevereiro de 1961, escrevia-se acerca do “grupo de alucinados" responsável pelos ataques: "alguns estavam verdadeiramente narcotizados [...], outros teriam bebido fortemente e davam mostras da bravura inconsciente mas inefetiva dos etilizados, mas outros ainda teriam tomado coca-cola na qual dissolveram comprimidos de aspirina - que constitui uma espécie de droga barata e que produz uma embriaguez heroica".

26 Cachipembe (ou caxipembe) é uma bebida alcoólica tradicional angolana, concretamente uma aguardente destilada a partir da fermentação de farelo de milho.

27 O termo "cafre" é de origem árabe, equivalente a "bárbaro", e era usado na África portuguesa para designar povos depreciativamente considerados "incultos" e "infiéis". 
A canábis circula pelo continente africano pelo menos desde o século XII, tendo sido inicialmente introduzida a partir da Ásia através de rotas de comércio árabes (Klantschnig 2014; Nahas 1982). Com o tempo, alguns povos africanos aprenderam a dominar os seus efeitos psicoativos e desenvolveram o seu consumo, nomeadamente de forma ritualizada (Emboden 1990 [1972]). $\mathrm{Na}$ Europa, pelo contrário, o consumo de canábis não se enraizou como costume cultural e é bastante recente (Pollan 2001), embora a sua utilização para fins comerciais, nomeadamente o aproveitamento das fibras do cânhamo, fosse quase milenar (Fontes e Carvalho 2011 [2002]). ${ }^{28}$

Também o consumo de bebidas alcoólicas era algo fortemente enraizado em África: o álcool afirmou-se sempre como a substância psicoativa mais consumida por todo o continente africano, nomeadamente na forma de vinhos, cervejas e licores de fabrico artesanal (Ambler, Carrier e Klantschnig 2014; Medeiros 1988; Capela 1973). No entanto, durante a Guerra Colonial, as tropas portuguesas não demonstraram para com as bebidas alcoólicas africanas o mesmo interesse que devotaram à canábis: limitaram-se a experimentá-las, mas, salvo raras exceções, não as adotaram e muito menos pensaram em trocá-las pelas suas próprias, nomeadamente a cerveja e o whisky.

Sensivelmente ao mesmo tempo que os soldados norte-americanos adotaram o consumo de drogas ilícitas na Guerra do Vietname, os militares portugueses depararam inesperadamente com a canábis num contexto de guerra, através das populações africanas negras. Experimentaram-na, deram-lhe uso, apropriaram-se dela e alguns trouxeram-na mesmo de volta a casa. De facto, alguns autores (Fontes e Carvalho 2011 [2002]) apontam os militares que regressavam da Guerra Colonial Portuguesa como os principais divulgadores do consumo de canábis (liamba) na "Metrópole" antes do 25 de Abril.

Tudo isto se passou nos finais da década de 60 e inícios de 70 do século XX, altura em que o mundo ocidental iniciava uma "cruzada" contra as drogas ilícitas, assente no proibicionismo. Embora o primeiro tratado internacional de controlo de drogas tenha sido acordado em 1912, foram as convenções da ONU de 1961 e 1971 que definitivamente estabeleceram um novo paradigma. Se para todos os efeitos o consumo de drogas ilícitas em Portugal continental era praticamente inexistente (Agra e Fernandes 1993), é neste período que o tema emerge como objeto do discurso político (Poiares 1995) - por pressão externa e provavelmente em função do alarme suscitado com a associação entre drogas e subversão juvenil a que se assistia noutros países - e se tomam as primeiras iniciativas, que culminam com a campanha "droga-loucura-morte", de 1972.

28 Em Uma Breve História da Cannabis em Portugal, Luís Torres Fontes e João Carvalho falam da improbabilidade que foi os europeus terem lidado "com a cannabis durante séculos sem se darem conta dos seus poderes psicoativos" (2011 [2002]: 176), o que só começou a mudar com a publicação em 1563 dos escritos do português Garcia de Orta sobre as plantas medicinais da Índia (Booth 2005). 
Ao mesmo tempo que o poder político fazia assentar o seu discurso sobre as drogas ilícitas numa linguagem bélica e num conjunto de metáforas militares (guerra, combate, inimigo), longe de casa, as tropas norte-americanas e portuguesas consumiam-nas sem grandes consequências disciplinares e, muito menos, criminais. Mais do que isso, no caso português, os jovens envolvidos na Guerra Colonial parecem ter sido mesmo os primeiros a consumir a canábis de forma expressiva (se se excluir os jovens nascidos ou residentes nas então colónias portuguesas de Angola e Moçambique).

De acordo com os testemunhos dos ex-combatentes, e pesem embora todas as dificuldades advindas de um tema manifestamente difícil e incómodo, pode dizer-se que os usos de álcool e canábis tinham o mesmo propósito: fazer esquecer, mesmo que temporariamente, a experiência da guerra e tornar possível a vida em tão duras condições. Para entender o consumo, é imprescindível conhecer as circunstâncias.

O que a história dos usos de álcool e canábis por parte de militares portugueses envolvidos na Guerra Colonial releva é o papel absolutamente central das motivações de consumo, das normas, dos significados e do enquadramento social (Klein 2012; MacRae 2001; Zinberg 1984). Dito de outra forma, as drogas - sejam elas de caráter lícito ou ilícito - não se podem reduzir às suas propriedades farmacológicas, pois a sua ação está intimamente dependente dos referentes socioculturais dos grupos sociais que as utilizam, contrariando as visões dominantes assentes nas visões médicas e criminais (Milhet et al. 2011 ; Romaní 1999).

Só assim se compreende que a canábis, uma droga que começa por ser tida como um "intoxicante" que instiga a violência do inimigo, seja mais tarde usada como uma fonte de "evasão" da violência do quotidiano. As drogas são sempre algo mais do que substâncias com determinadas propriedades farmacológicas, e o contexto histórico e social é tudo. Ou quase tudo.

Em resumo, os usos de álcool e canábis na Guerra Colonial Portuguesa são mais um episódio da história das drogas assente nas trocas, no fluxo e na circulação dos produtos - neste caso, as bebidas alcoólicas que são levadas de Portugal continental para as (então) colónias africanas, incluindo as mais remotas áreas onde estivessem militares portugueses, e uma planta com propriedades psicoativas que circula das populações negras africanas para os quartéis portugueses. E é uma história que, para ser compreendida, deverá ser contada atendendo, por um lado, ao contexto político, social e económico e, por outro, às experiências e às motivações dos consumidores. É esse o desafio da antropologia num terreno minado como é o campo das drogas, há muito tempo dominado pelo biopoder. 


\section{BIBLIOGRAFIA}

AFOnSO, Aniceto, e Carlos Matos GOMES, 2000, Guerra Colonial. Lisboa, Editorial Notícias.

AGRA, Cândido, e Luís FERNANDES, 1993, "Droga enigma, droga novo paradigma”, em

C. Agra (org.), Dizer a Droga, Ouvir as Drogas. Porto, Radicário, 56-86.

AGUIAR, Cristóvão, 2007, Braço Tatuado: Retalhos da Guerra Colonial. Lisboa, Dom Quixote.

ALEXANDre, Dora, 2015, O Outro Lado da Guerra: Memórias para Além das Armas e dos Combates. Lisboa, A Esfera dos Livros.

AMBLER, Charles, Neil CARRIER, e Gernot KLANTSCHNIG, 2014, "Introduction”, em G. Klantschnig, N. Carrier e C. Ambler (orgs.), Drugs in Africa: Histories and Ethnographies of Use, Trade, and Control. Nova Iorque, Palgrave Macmillan, 1-23.

ANTunes, António Lobo, 2005, D’Este Viver Aqui Neste Papel Descripto. Lisboa, Dom Quixote.

ANTUNES, José Freire, 1995, A Guerra de África: 1961-1974. Lisboa, Círculo de Leitores, 2 vols.

ANTUNES, Luís Dias, 2006, "A Ilha de Moçambique na segunda metade do século XVIII", Anais da História de Além-Mar, VII: 197-212.

ANTUNeS, Maria José Lobo, 2015, Regressos Quase Perfeitos: Memórias da Guerra em Angola. Lisboa, Tinta da China.

ARANHA, Eduardo Brito, 2005, Um Barco Fardado. Lisboa, Roma Editora.

BASTOS, Manuel, 2008, Cacimbados: A Vida por Um Fio. Vila Nova de Gaia, Babel Editores.

BERGEN-CICO, Dessa, 2012, War and Drugs: The Role of Military Conflict in the Development of Substance Abuse. Boulder, CO, Paradigm Publishers.

BOOTH, Martin, 2005, Cannabis: A History. Nova Iorque, Picador.

CAlado, Vasco Gil, 2006, Drogas Sintéticas: Mundos Culturais, Música Trance e Ciberespaço. Lisboa, Instituto da Droga e da Toxicodependência.

CALADO, Vasco Gil, 2009, "Em torno do cultivo de cannabis: uma análise do ciberespaço como ponto de partida para uma investigação", Toxicodependências, 15 (1): 43-52.

CAlado, Vasco Gil, 2013, Novas Substâncias Psicoativas: O Caso da Salvia Divinorum. Lisboa, Serviço de Intervenção nos Comportamentos Aditivos e nas Dependências.

CAPELA, José, 1973, O Vinho para o Preto: Notas e Textos sobre a Exportação do Vinho para África. Porto, Afrontamento.

CAPELO, Hermenegildo, e Roberto IVENS, 2010 [1881], De Benguella ás Terras de Iácca: Descripção de uma Viagem na Africa Central e Occidental, volumes I e II. Mem Martins, Publicações Europa-América.

CARVAlHo, Henrique, 1898, O Jagado de Cassange na Provincia de Angola. Lisboa, Typographia de Cristovão Augusto Rodrigues.

COHEN, Stanley, 2002 [1972], Folk Devils and Moral Panics: The Creation of the Mods and Rockers. Londres, Routledge ( 3 . $^{\mathrm{a}}$ edição).

COSTA, Carlos, 2007, A Droga, o Poder Político e os Partidos em Portugal. Lisboa, Instituto da Droga e da Toxicodependência.

COUCEIRO, Henrique de Paiva, 1892, Relatório de Viagem entre Bailundo e as Terras do Mucusso. Lisboa, Imprensa Nacional.

COURTWRIGHT, David, 2001, Forces of Habit: Drugs and the Making of the Modern World. Cambridge, MA, Harvard University Press. 
CRUZ, Olga Sousa, Carla MACHADO, e Luís FERNANDES, 2012, "O 'problema da droga': sua construção, desconstrução e reconstrução”, Análise Psicológica, 30 (1-2): 49-61.

DEVILlard, M. José, Adela MUDANÓ, e Álvaro PAZOS, 2012, "Apuntes metodológicos sobre la conversación en el trabajo etnográfico”, Política y Sociedad, 49 (2): 353-369.

DIAS, Lúcia, 2007, As Drogas em Portugal: O Fenómeno e os Factos Jurídico-Políticos de 1970 a 2004. Coimbra, Pé de Página.

EMBODEN, William, 1990 [1972], "Ritual use of Cannabis sativa, L.: a historical-etnographic survey" em Peter Furst (org.), Flesh of the Gods: The Ritual Use of Hallucinogens. Prospect Heights, IL, Waveland Press, 214-236.

ESCOHOTADO, Antonio, 2004 [1996], História Elementar das Drogas. Lisboa, Antígona.

FABIAN, Johannes, 2000, "Charisma, cannabis, and crossing of Africa”, em J. Fabian, Out of Our Minds: Reason and Madness in the Exploration of Central Africa. Berkeley, University of California Press, 151-179.

FEIXA, Carles, 1998, De Jóvenes, Bandas y Tribus. Barcelona, Editorial Ariel.

FERNANDES, Luís, 2009, “O que a droga faz à norma”, Toxicodependências, 15 (1): 3-18.

FERreIRA, Alcino, 2011, A Minha Guerra: Um Testemunho da Guerra Colonial por Quem a Viveu. Lisboa, Clube do Autor.

FONTES, Luís Torres, e João CARVALHO, 2011 [2002], "Uma breve história da cannabis em Portugal”, em J. Herer, O Rei Vai Nu: O Cânhamo e a Conspiração contra a Marijuana. Porto, Via Óptima, 17 1-204 (3. a edição).

GANHÃO, Carlos, 2007, Dembos: A Floresta do Medo - Angola 1969 a 1971. Lisboa, Terramar. GARCIA, Francisco Proença, 2010, A Guerra de Moçambique, 1964-1974. Matosinhos, Quidnovi.

GEZON, Lisa, 2016 [2012], Drug Effects: Khat in Biocultural and Socioeconomic Perspective. Nova Iorque, Routledge.

GOMES, Carlos Matos, 2013, "A africanização na Guerra Colonial e as suas sequelas: tropas locais - os vilões nos ventos da história”, em M. P. Meneses e B. S. Martins (orgs.), As Guerras de Libertação e os Sonhos Coloniais: Alianças Secretas, Mapas Imaginados. Coimbra, CES/Almedina, 123-141.

HEINTZE, Beatrix, 2010 [1999], Exploradores Alemães em Angola (1611-1954): Apropriações Etnográficas entre Comércio de Escravos, Colonialismo e Ciência, e-book disponível em $<$ http://www.frobenius-institut.de/images/downloads/exploradores.pdf > (última consulta em outubro de 2016).

HUNT, Geoffrey, e Judith BARKER, 2001, "Socio-cultural Anthropology and alcohol and drug research: towards a unified theory”, Social Science \& Medicine, 53: 165-188.

INGLIS, Brian, 1975, The Forbidden Game: A Social History of Drugs. Nova Iorque, Charles Scribner's Sons.

JAMES, William, e Stephen JOHnSON, 1996, Doin' Drugs: Patterns of African American Addiction. Austin, University of Texas Press.

JANEIRO, António, 2012, Regresso a Angola (Por Não Ter Partido). Lisboa, Edições Vieira da Silva.

KAN, Paul, 2009, Drugs and Contemporary Warfare. Dulles, VA, Pontomac Books.

KLANTSCHNIG, Gernot, 2014, "Histories of cannabis use and control in Nigeria, 1927 -1967”, em G. Klantschnig, N. Carrier e C. Ambler (orgs.), Drugs in Africa: Histories and Ethnographies of Use, Trade, and Control. Nova Iorque, Palgrave Macmillan, 69-88. 
KLEIN, Axel, 2012, "The Anthropology of drugs", em R. Fardon et al. (orgs.), The Sage Handbook of Social Anthropology, vol. II. Los Angeles, Sage, 365-376.

KRANZLER, Henry, e Pamela KORSMEYER, 2009, Encyclopedia of Drugs, Alcohol \& Addictive Behavior (Third Edition). Nova Iorque, Macmillan Reference/Gale Cengage Learning Library.

KUZMAROV, Jeremy, 2009, The Myth of the Addicted Army: Vietnam and the Modern War on Drugs. Boston, University of Massachusetts Press.

KVALE, Steinar, 2006, "Dominance through interviews and dialogues", Qualitative Inquiry, 12 (3): 480-500.

LEWIS, Bernard, 2003 [1967], The Assassins: A Radical Sect in Islam. Nova Iorque, Basic Books. LOJA, António, 2013 [2002], As Ausências de Deus: No Labirinto da Guerra Colonial. Lisboa, Âncora Editora (2. ${ }^{\mathrm{a}}$ edição).

LOPES, Daniel Seabra, 1998, Ex-Combatentes da Guerra Colonial: Experiência e Identidades: Ensaio de Construção de Um Objecto Antropológico. Lisboa, ISCTE, tese de mestrado.

LOVEJOY, Paul, 2007 [1995], "Kola nuts: the 'coffee' of the Central Sudan”, em J. Goodman, P. Lovejoy e A. Sherratt (orgs.), Consuming Habits: Global and Historical Perspectives on How Cultures Define Drugs. Londres, Routledge, 98-120.

MacRAE, Edward, 2001, "Antropologia: aspectos sociais, culturais e ritualísticos", em S. Seibel e A. Toscano Jr., Dependência de Drogas. São Paulo, Editora Atheneu, 25-34.

MANNIng, Paul, 2014, Drugs and Popular Culture in the Age of New Media. Nova Iorque, Routledge.

MARANISS, David, 2003, They Marched into Sunlight: War and Peace, Vietnam and America, October 1976. Nova Iorque, Simon \& Schuster.

MARTA, Alexandre, 2000, A Arma. Lisboa, Roma Editora.

MARTIN, A. Lee, 2012, Smoke Signals: A Social History of Marijuana - Medical, Recreational, and Scientific. Nova Iorque, Scriber.

MARTINS, José Manuel, 2003, Zau-Évua: Terra de Ninguém, Sítio de Vivências. Seixal, Letras d'Ouro.

MATA, Lobo, 2012, A Guerra de Lob. Lisboa, Chiado Editora.

MEDEIROS, Eduardo, 1988, Bebidas Moçambicanas de Fabrico Artesanal. Maputo, Arquivo Histórico de Moçambique.

MILHET, Milena, et al., 201 1, "Introduction”, em G. Hunt, M. Milhet e H. Bergeron (orgs.), Drugs and Culture: Knowledge, Consumption and Policy. Farnham, Ashgate, 1-12.

MONTEIRO, Miguel, 2001, "Não voltes para casa: um relato de fim de Império", em R.A. Teixeira (org.), A Guerra do Ultramar: Realidade e Ficção. Lisboa, Editorial Notícias, 269-278 .

NAHAS, Gabriel, 1982, "Hashish in Islam: 9th to 18th century", Bulletin of the New York Academy of Medicine, 58 (9): 814-831.

NIZA, José, 2012, Golden Gate: Um Quase Diário de Guerra. Alfragide, Dom Quixote.

NUTT, David, 2012, Drugs, without the Hot Air: Minimizing the Harms of Legal and Illegal Drugs. Cambridge, UIT Cambridge.

OEIRAS, Luís, 2009, Mueda-Lua. Lisboa, Roma Editora.

PEREIRA, Rogério, 201 1, Almas Que Não Foram Fardadas. Oeiras, Espaço e Memória - Associação Cultural de Oeiras.

POIARES, Carlos, 1995, "A legislação penal da droga: contribuição para uma análise do discurso do legislador", Toxicodependências, 3: 17-29. 
POLlAN, Michael, 2001, The Botany of Desire: a Plant's-Eye View of the World. Nova Iorque, Random House.

RASMUSSEN, Nicolas, 2008, On Speed: The Many Lives of Amphetamine, Nova Iorque, New York University Press.

RIBEIRO, João Salvado, 1995, "Dependência ou dependências? Incidências históricas na formalização do conceito", Toxicodependências, 1 (3): 5-16.

RIBEIRO, Jorge, 1999, Marcas da Guerra Colonial. Lisboa, Campo das Letras.

ROBINS, Lee, 1993, “Vietnam veterans' rapid recovery from heroin addiction: a fluke or normal expectation?", Addiction, 88: 1041-1054.

RODrigues, Fátima, 2012, Antigos Combatentes Africanos das Forças Armadas Portuguesas: A Guerra Colonial como Território de (Re)Conciliação. Coimbra, Universidade de Coimbra, tese de doutoramento.

RODRIGUES, Thiago, 2008, “Tráfico, guerra, proibição”, em B. Labate et al. (orgs.), Droga e Cultura: Novas Perspectivas. Salvador, Editora da Universidade Federal da Bahia, 91-104.

ROMANÍ, Oriol, 1999, Las Drogas: Sueños y Razones. Barcelona, Editorial Ariel.

ROQUe, Sara, 2004, A Guerra Colonial e os Seus Silêncios: Contributo para o Estudo de Uma Antropologia do Silêncio. Lisboa, ISCTE, tese de mestrado.

ROSA, Frederico Delgado, e Filipe VERDE, 2013, Exploradores Portugueses e Reis Africanos: Viagens ao Coração de África no Século XIX. Lisboa, A Esfera dos Livros.

RUBIO, Maria Isabel, 2006, "La imposición de los puntos de vista durante la entrevista etnográfica”, Antropologia Portuguesa, 22-23: 9-40.

SÁ, Sérgio O., 2009, De Quibala a Melele (Norte de Angola) no Decorrer de Uma Guerra. S/1., edição de autor.

SANTOS, João dos, 1999 [1609], Etiópia Oriental e Vária História de Cousas Notáveis do Oriente. Lisboa, Comissão Nacional para as Comemorações dos Descobrimentos Portugueses.

SANTOS, Vítor, 2013, “O Bafo do África”: Histórias de Um Sapador. Lisboa, RCP Edições.

SILVA, Elisete, 2003, "Impactos da ocupação colonial nas sociedades rurais do Sul de Angola”. Lisboa, ISCTE/Centro de Estudos Africanos, occasional paper series n. ${ }^{\circ} 8$, disponível em <http://www.casadasafricas.org.br/wp/wp-content/uploads/2011/08/Impactos-da-ocupacao-colonial-nas-sociedades-rurais-do-sul-de-Angola.pdf $>$ (última consulta em outubro de 2016).

SILVA, Tiago Matos, 2007, "Exilados em casa: os veteranos da Guerra Colonial e os limites da 'Nação' ", Arquivos da Memória, 1 (nova série): 31 -39.

SOUSA, Jorge Trigo, 2007, A Guerra Colonial. Linda-a-Velha, DG Edições.

STANTON, Morris, 1976, "Drugs, Vietnam and the Vietnam veteran: an overview", American Journal of Drugs and Alcohol Abuse, 3 (4): 279-286.

TEIXEIRA, Rui Azevedo (org.), 2001, A Guerra do Ultramar: Realidade e Fiç̧ão. Lisboa, Editorial Notícias.

TOIT, Brian du, 1975, "Dagga: the history and ethnographic setting of Cannabis sativa in Southern Africa", em V. Rubin (org.), Cannabis and Culture. Haia, Mouton Publishers, 81-116.

TOIT, Brian du, 1976, "Man and cannabis in Africa: a study of diffusion", African Economic History, 1: 17-35.

VALAHU, Mugur, 1968, Angola: Chave de África. Lisboa, Edição A. M. Pereira. 
VALENTIM, Cristina, 2012, “Corpo, folclore e identidade: relações de poder na Lunda colonial, Angola, 1944-1975”, comunicação apresentada no 8. ${ }^{\circ}$ Congresso Ibérico de Estudos Africanos, Madrid, Universidade Autónoma de Madrid, disponível em < http://www. ces.uc.pt/myces/UserFiles/livros/1097_com.\%20acta\%20madrid.pdf > (última consulta em outubro de 2016).

VARDASCA, Carlos, 2010, “Como iludir os nossos medos", em Do Tejo ao Rovuma (blogue), disponível em < http://dotejoaorovuma-cabel.blogspot.pt/2010/02/como-iludir-os-nossos-medos.html > (última consulta em outubro de 2016).

VARDASCA, Carlos, 2012, Do Tejo ao Rovuma: Uma Breve Pausa Num Tempo das Nossas Vidas. S/l., edição de autor.

WELWITSCH, Frederico, 1862, Synopse Explicativa das Amostras de Madeiras e Drogas Medicinaes e de Outros Objectos Mormente Ethnographicos Colligidos na Provincia de Angola Enviados á Exposição Internacional de Londres em 1862. Lisboa, Imprensa Nacional.

WHAlON, Pete, 2004, The Saigon Zoo: Vietnam's Other War. Sex, Drugs, Rock ' $n$ ' Roll. West Conshohocken, Infinity Publishing.

WHEELER, Douglas, e René PÉLISSIER, 2009 [1971], História de Angola. Lisboa, Tinta da China.

WILliAmS, Ian, 2005, Rum: A Social and Sociable History. Nova Iorque, Nation Books. ZINBERG, Norman, 1984, Drug, Set and Setting. New Haven, Yale University Press. 